\title{
OBSERVAÇÃO SOBRE O PADRÃO FÁGICO DE CEPAS DE STAPHYLOCOCCUS AUREUS ISOLADAS DA BOCA E DO NARIZ DE INDIVIDUOS SÃOS
}

Flávio Zèante *

Hassib A: :icar*

Benedito joś: de Azevedo Piochi *

Marcia Pinto Alves*

ZELANTE, F. et al. Observação sobre o padrăo fágico de cepas de Ctaphylococcus aureus isoladas da boca e do nariz de individuos sãos. Rev. Saúde pábl., $S$. Paulo, $17: 123-9, \quad 1983$

RESUMO: Foram analisadas 68 cepas de Staphylococcus aureus isoladas da boca (saliva e língua) e nariz de portadores assintomáticos que albergavam essa bactéria nos três nichos, simultaneamente. Embora os três nichos apresentassem equivalência quanto ao percentual de isolamentos, foi constatado que as cepas isoladas do nariz diferiam, quanto ao seu padrão fágico, principalmente daquelas isoladas da língua. No primeiro caso, as cepas apresentaram-se mais sensíveis aos fagos do grupo I enquanto que, as isoladas do segundo nicho, foram mais sensiveis aos fagos do grupo III. Considerando estas observaçóes é recomendável, quando da detecção de portadores de Staphylococcus aureus, a pesquisa dessa bactéria em material colhido do nariz e da boca, simultaneamente.

UNITERMOS: Staphylococcus aureus. Portadores.

\section{INTRODUÇÃO}

A importância médico-sanitária do Staphylococcus aureus, face à sua patogenicidade para o homem e os animais, tem sido destacada, principalmente porque devido a sua elevada taxa de mutabilidade, tem aumentado consideravelmente o número de cepas resistentes aos agentes antibióticos ${ }^{8,13}$.

Em consequiência, ao longo dos anos tem sido constante a preocupação dos pesquisadores na detecção de portadores dessa bactéria, principalmente entre o pessoal profissional relacionado ao ambiente médico-hospitalar $1,8,11$ e ao de indústria de alimen$\operatorname{tos} 3,4$.
Devido à maior facilidade de obtenção de material para exame $e$, também, por se tratar de nicho com elevada possibilidade de colonização e de dispersão da bactéria, as fossas nasais foram eleitas como local ideal para a pesquisa de portadores assintomáticos de $S$. aureus 4,6 .

Todavia, trabalhos de Knighton 5,6,7 (1960, 1962, 1965), Piochi e Zelante ${ }^{9,10}$ (1973, 1975) e Zelante e col.14 (1982), mostraram a importância da cavidade bucal, como reservatório de $S$. aureus, tendo-a considerado em nível equivalente às fossas nasais. Estes últimos autores, visando tornar mais abrangente a pesquisa dos portadores,

\footnotetext{
* Do Departamento de Microbiologia e Imunologia "Setor Odontologia" do Instituto de Ciências Biomédicas da USP - Cidade Universitária "Armando de Sales Oliveira" - 05508 - São Paulo, SP - Brasil.
} 
ZELANTE, F. et al. Observação sobre o padrăs fágico de cepas de staphylococcus aureus isolađas da boca e do nariz de indiviōuos săos. Rcv. Saúde pribl., S. Paulo, 17:123-9, 1983.

recomendaram a obtenção de material, simultaneamente das fossas nasais e da cavidade bucal (lingua ou saliva). Esta conduta se revestiria de maior significado e justificando-se plenamente se as áreas bucal e nasal estiverem simultaneamente colonizadas por cepas distintas de Staphylococcus aureus.

Assim, o presente trabalho foi conduzido no sentido de verificar o tipo ou o padrão fágico dos estafilococos patogênicos isolados do nariz, da saliva e da língua de portadores assintomáticos, procurando-se determinar eventuais identidades entre essas cepas.

\section{MATERIAL E MATODOS}

\section{Cepas de Staphylococcus aureus estudadas}

De 130 indivíduos sem sinais ou sintomas relacionados a lesões nas áreas bucal e nasal, foi colhido material das fossas nasais, da saliva e de raspado de língua e, em seguida, semeado em meio de Staphylococcus 110 (Difco) para isolamento de $S$. aureus, conforme 0 descrito em trabalho anterior ${ }^{14}$. As cepas isoladas foram identificadas de acordo com as recomendações do Subcomitê Internacional de Taxonomia de Staphylococcus e Micrococcus ${ }^{1 / 2}$ (1965).

\section{Identidade entre as cepas isoladas}

Foi verificada através da fagotipagem ${ }^{2}$ a 1 x RTD e 100 x RTD (Routine Test Dilution), com os seguintes fagos*:

Conjunto básico internacional:

$$
\begin{gathered}
\text { Grupo I }-29,52,52 \mathrm{~A}, 79,80 \\
\text { Grupo II }-3 \mathrm{~A}, 3 \mathrm{C}, 55,71 \\
\text { Grupo III }-6,42 \mathrm{E}, 47,53,54,75,77, \\
\quad 83 \mathrm{~A}, 84,85
\end{gathered}
$$

Fagos não classificados: $81,94,95$ e 96 .

Conjunto experimental: $86,88,89,90,92$, D11, HK2.

\section{RESULTADOS}

Foram analisadas 68 cepas de Staphylococcus aureus isolados de portadores que albergavam essa bactéria, simultaneamente, nos três nichos.

A Tabela 1 apresenta a origem dessas cepas.

TA B L A 1

Cepas de Staphyloooccus aureus isoladas de 130 indivíduos sãos, segundo o número de isolamento.

\begin{tabular}{llc}
\hline & \multicolumn{2}{c}{ Cepas isoladas } \\
\cline { 2 - 3 } & Nicho & NQ \\
\hline Fossas nasais & 21 & 30,88 \\
Salliva & 26 & 38,24 \\
Lingua & 21 & 30,88 \\
\hline Total & 68 & 100,00 \\
\hline
\end{tabular}

A Tabela 2 apresenta as frequiências em que as cepas de $S$. aureus foram lisadas quando submetidas ao conjunto básico internacional, aos fagos não classificados e ao conjunto experimental.

A Fig. 1 mostra o número de vezes em que as cepas isoladas foram sensiveis, em conjunto, aos fagos dos grupos I, II e III, do conjunto básico e as Figs. 2, 3 e 4 apresentam, respectivamente, a sensibilidade individual de cada uma das cepas de $S$. aureus aos mesmos fagos.

Devido ao pequeno número de reações de lise observadas com os fagos não classificados e do grupo experimental, não foram incluidas as Figuras representativas dessas reações.

\footnotetext{
* Realizada na Seção de Fagotipagem do Laboratório de Estreptococos e Estafilococos do Departamento de Parasitologia, Microbiologia e Imunologia da Faculdade de Medicina de Ribeirăo Preto da USP.
} 
ZELANTE, F. et al. Observaçóo sobre o padrăo fágico de cepas de staphylococcus aureus lsoladas da boca e do nariz de individuos stos. Rev. Sanide pribl., S. Paulo, 17:123-9, 1983.

\section{T A B E I A 2}

Frequéncia de reaçóes de sensibilidade fágica apresentada por cepas de $\boldsymbol{s}$. aureus isoladas do nariz, da sallva e da língua, de portadores assintomáticos.

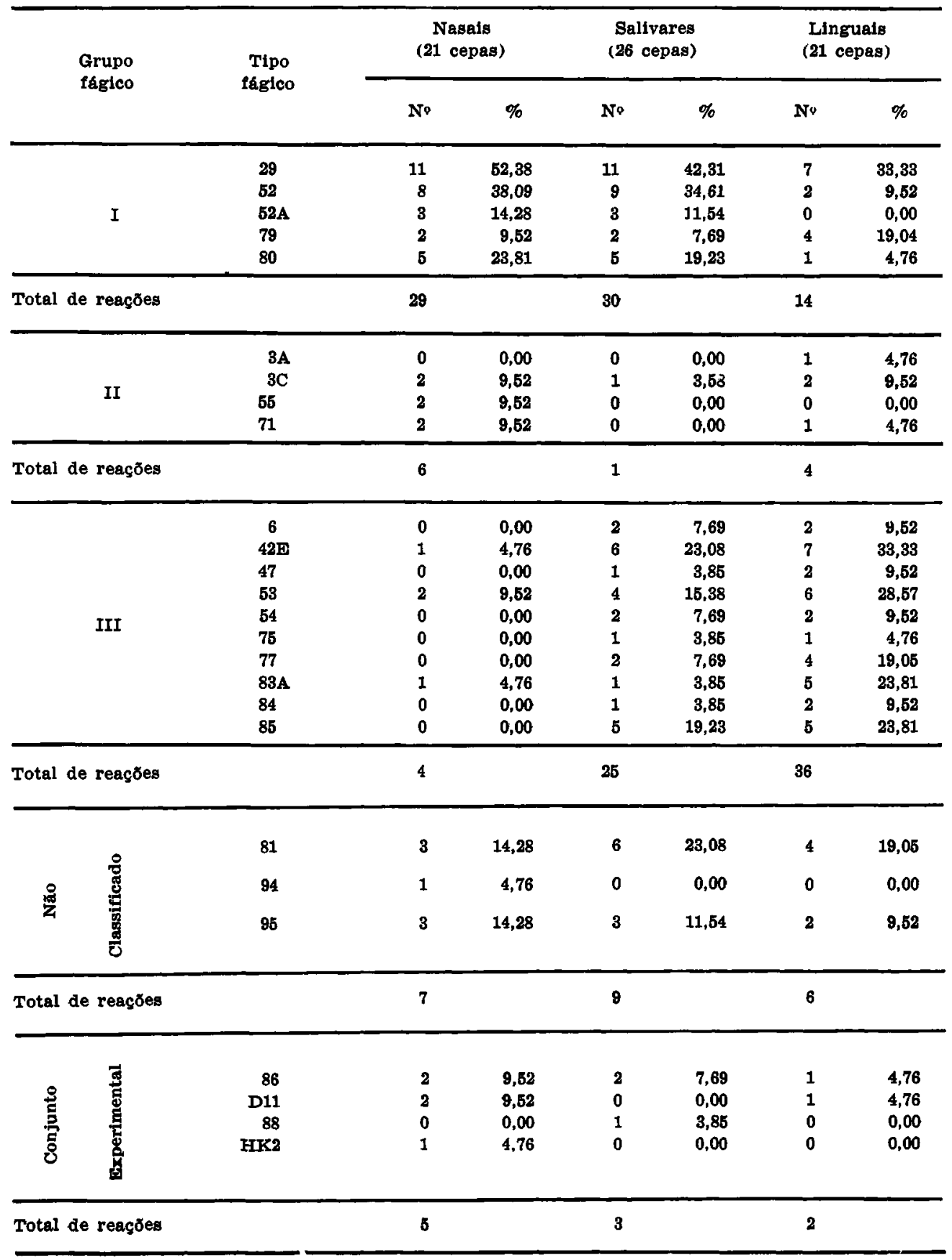




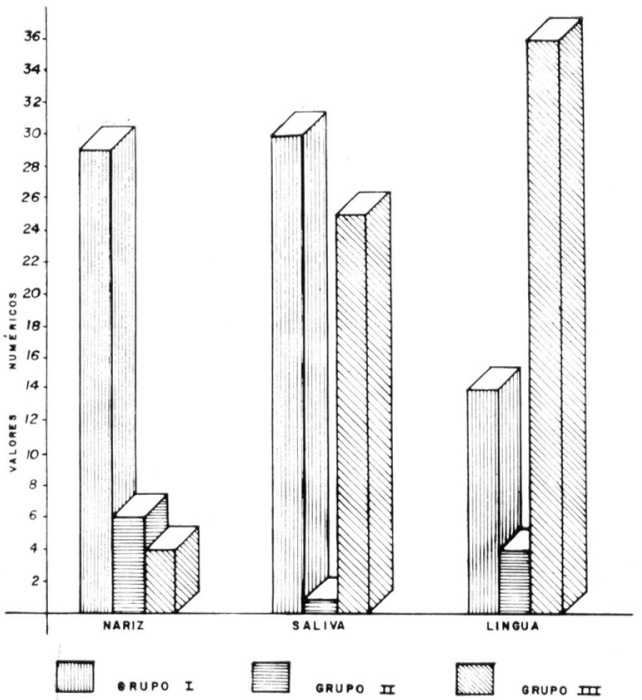

Fig. 1 - Número de rezes em que cepas de S. aureus isoladas do nariz, saliva e lingua foram sensiveis a fagos dos grupos I, II e III do conjunto básico internacional.

\section{DISCUSSAO E CONCLUSOES}

De forma genérica, os três nichos estudados mostraram ser equivalentes como reservatórios de $S$. aureus e o fato da saliva apresentar número de isolamentos ligeiramente superior, pode ser considerado como conseqüência da sua própria ação mecânica de lavagem da área bucal.

Knighton ${ }^{5}$ (1965) verificou a frequiência média de $47,5 \%$ de portadores salivares de $S$. aureus tendo, todavia, analisado saliva obtida com estímulo mastigatório. Ao contrário, em nossas observaçoes, a saliva foi obtida sem estímulo, o que diminui a possibilidade de serem incorporadas ao inóculo bactérias originalmente localizadas em su. perfícies como a placa dental e a mucosa. A par destas considerações e tendo a análise do material obtido por raspagem da lingua revelado percentagem de isolamento similar à observada para as fossas nasais, é permitido aceitar como sendo

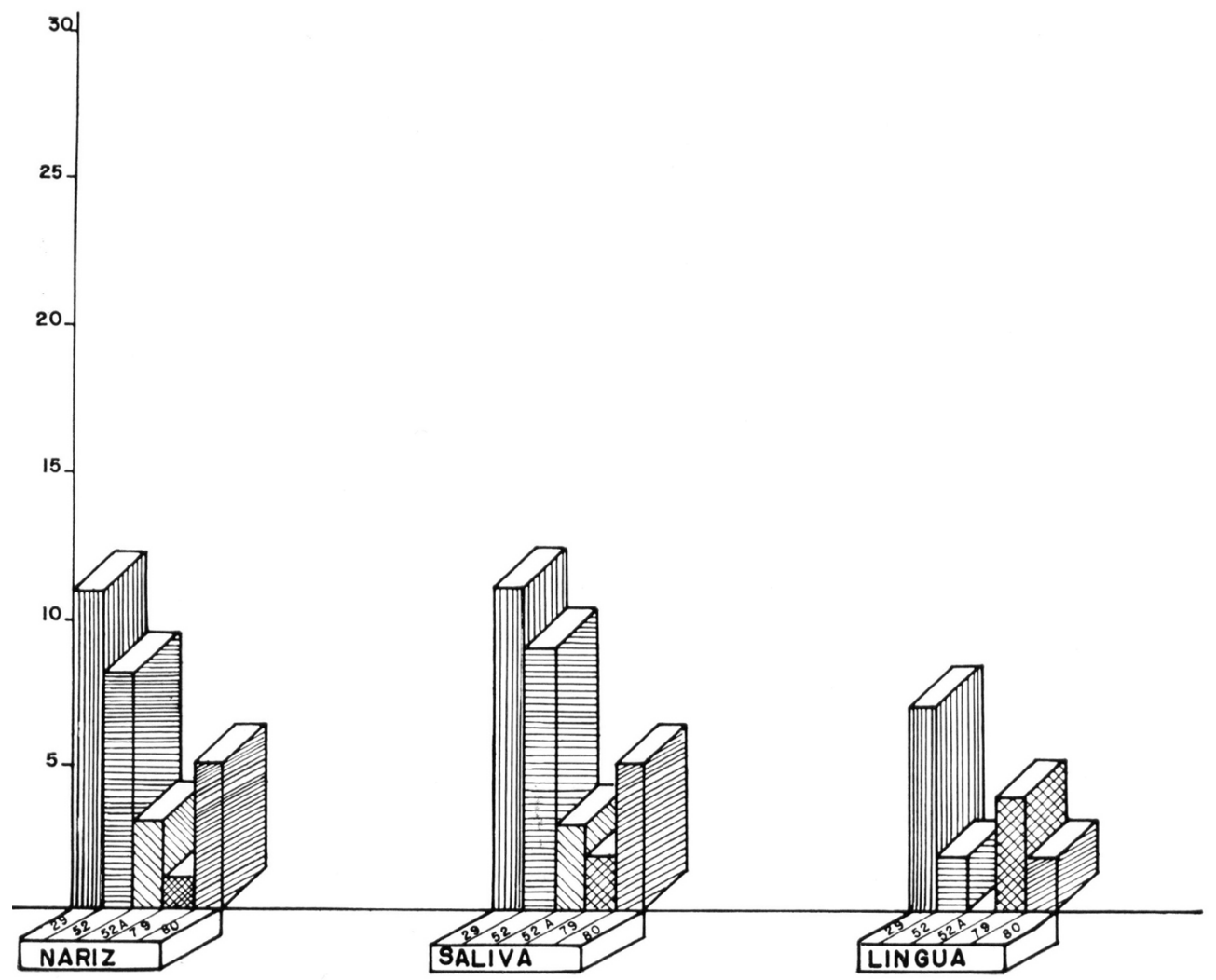

Fig. 2 - Distribuição percentual de cepas sensiveis acs bacteriofagos do grupo I do conjunto básico internaçional. 


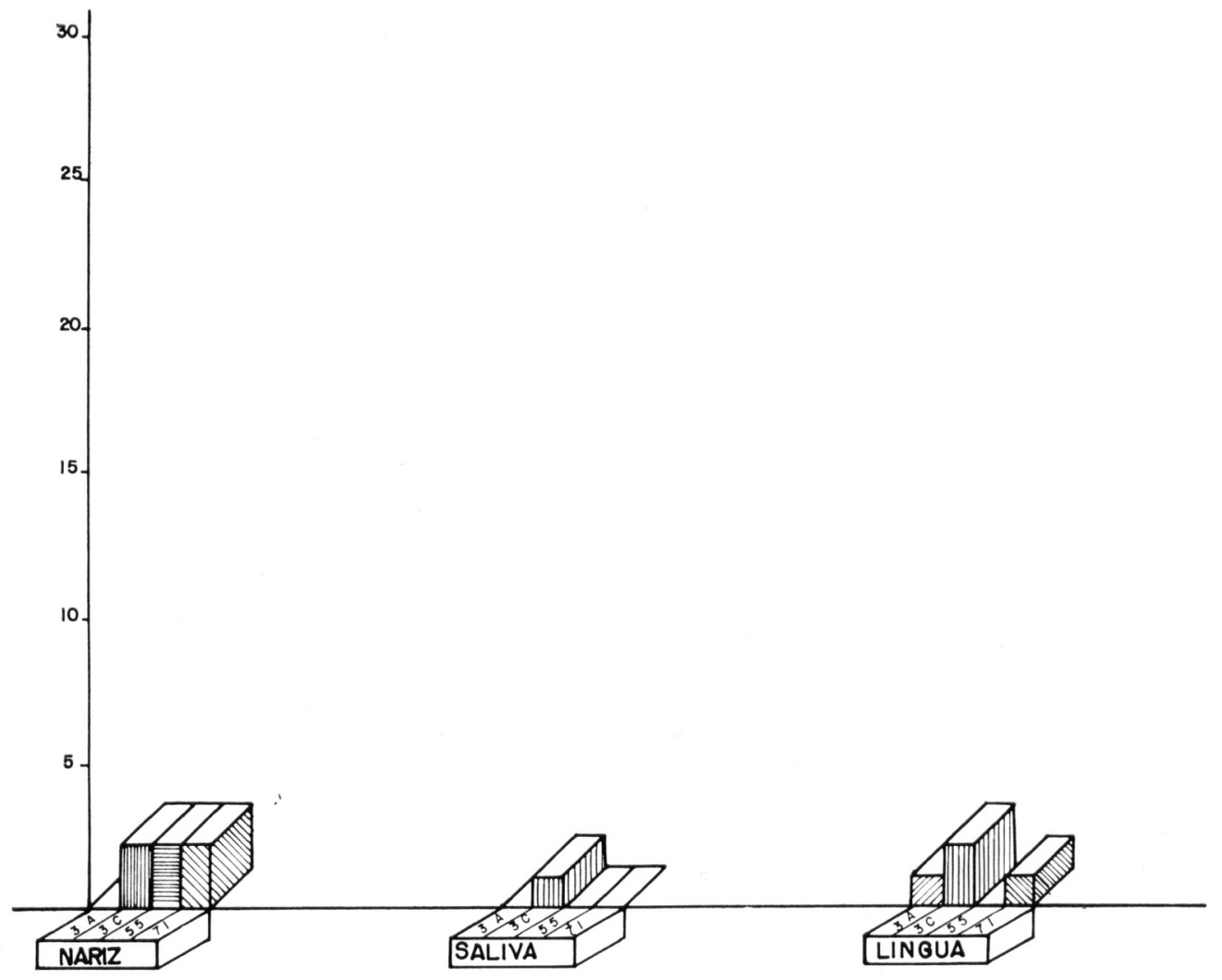

Fig. 3 - Distribuição percentual de cepas sensíveis aos bacteriófagos do grupo II do conjunto básico internacional.

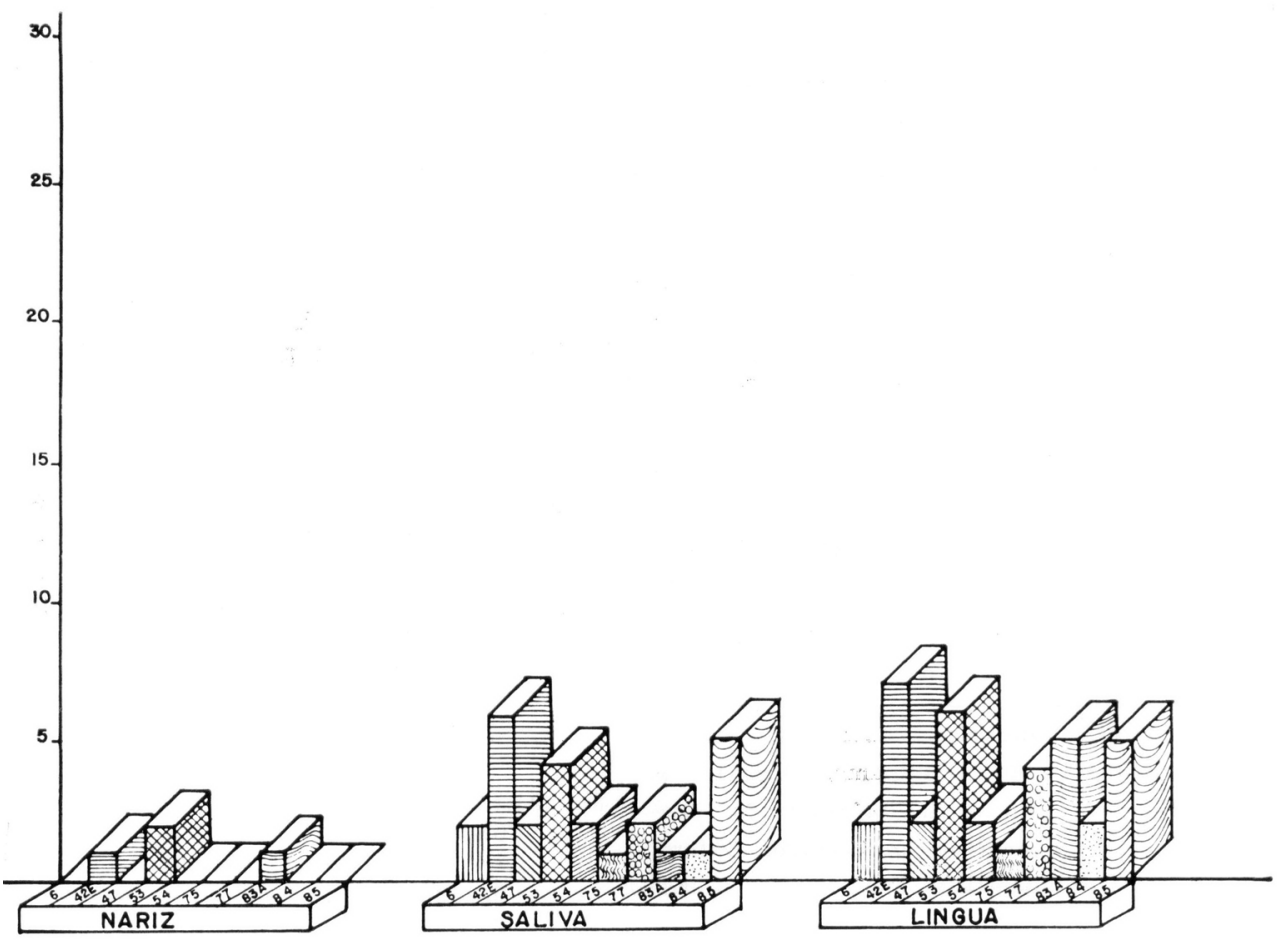

Fig. 4 - Distribuição percentual de cepas sensiveis aos bacteriófagos do grupo III do conjunto básico internacional. 
ZELANTE, F. et al. Observaçăo sobre o padráo fágico de cepas de staphylococcus aureus isoladas da boca e do nariz de Individuos stoos. Rev. Sauide pribl., S. Paulo, 17:123-9, 1983.

maior a incidência de $S$. aureus na cavidade bucal, mesmo excluindo-se os tipos fágicos iguais, dentre os portadores salivares e linguais desta bactéria.

As cepas isoladas do nariz reagiram em 29 dos testes com fagos do grupo I, em 6 com fagos do grupo II e em apenas 4 dos testes com fagos do grupo III. Estes resultados indicam predomínio de sensibilidade a bacteriófagos do grupo I, entre estafilococos isolados das fossas nasais, com maior número de cepas $(50 \%)$ reagentes com o fage 29.

Quanto às cepas isoladas da saliva, verificou-se que foram sensiveis, em 30 reaçōes, com fagos do grupo I, em uma reação com um dos fagos do grupo II e em 25 com fagos do grupo III mostrando, assim, serem muito reagentes tanto com fagos do grupo 1 como do grupo III. Nos testes com fagos do grupo I, houve predominio de cepas sensiveis ao fago $29(42,3 \%)$ e nos testes com fagos do grupo III foi observado maior número de cepas reagentes com o fago $42 \mathrm{E}$ $(23,0 \%)$.

Entre as cepas de $S$. aureus isoladas da língua, verificou-se 14 reações positivas com fagos do grupo I, $4 \mathrm{com}$ fagos do grupo II e $36 \mathrm{com}$ fagos do grupo III. Estas cepas mostram, portanto, maior sensibilidade a fagos do grupo III, destacando-se as sensiveis ao fago $42 \mathrm{E}(30,4 \%)$.

Os resultados apresentados mostraram que a cavidade bucal alberga fagotipos $d z$ $S$. aureus diferentes dos encontrados nas fossas nasais (grupo III e I, respectivamente). Este fato torna evidente a necessidade de se pesquisar $S$. aureus em material colhido simultaneamente da boca e do nariz, quando da detecção de portadores assintomáticos desta bactéria.

ZELANTE, F. et al. [Observations about the phage pattern of Staphylococcus aureus strains isolated from mouth and nose in clinically healthy individuals]. Rev. Saćde púb., S. Paulo, 17:123-9, 1983.

ABSTRACT: Sixty-eight Staphylococcus aureus strains, isolated from mouth and nose in clinically healthy individuals were submitted to phagetyping. Although the three niches, togne, saliva and nose, showed equivalent percentual of isolation, the nose and the mouth harbour different phage patterns from the International Phagetyping Set. The strains isolated from the nose were more sensitive to the phages from group $I$, whereas the strains isolated from the tongue were more sensitive to the phages from group III. Based on these observations, research on nose and mouth (tongue and saliva) simultaneously is recommended, where $\mathbf{s}$. aureus carriers are detected

UNITERMS: Staphylococcus aureus, Carrier state.

\section{REFERANCIAS BIBLIOGRAFICAS}

1. ALTERMEIER, W.A. Prevention of post operative infection: operating "theater practice". In: Williams, R.F.O. \& Shooter, R.A., ed. Infection in hospitals: epidemiology and control. Oxford, Blackwell Scientific Publ., 1963. p. 207$-20$.
2. BLAIR, J.E. \& WILliaMs, R.F.O. Phage typing of staphylococci. Bull. Wld Fith Org., 24:771-84, 1961.

3. IARIA, S.T. Staphylococcus aureus enterotoxigenico em doces cremosos vendidos em padarias e confeltarias do município de sáo Paulo, Brasil. Rev. Sauide pübl., S. Paulo, 15:321-37, 1981. 
ZELANTE, F. et al. Observação sobre o padrão fágico de cepas de staphylococcus aureus isoladas da boca e do nariz de indivíduos sãos. Rev. Saúde públ,, S. Paulo, 17:123-9, 1983.

4. IARIA, S.T.; FURLANETTO, S.M.P. \& CAMPOS, M.L.C. Pesquisa de Staphylococous aureus enterotoxigênico nas fossas nasais de manipuladores de alimentos em hospitais, S. Paulo, 1976. Rev. Saude públ., S. Paulo, 14:93-100, 1980.

5. KNIGHTON, H.T. Coagulase-positive Staphylococci in oral and nasal areas of dental students: a four year study. $J$. dent. Res., 44:467-70, 1965.

6. KNIGHTON, H.T. Relative constancy of specific bacteriophage paterns of Staphylococel isolated from oral and nasal areas. J. dent. Res., 41:701-6, 1962.

7. KNIGHTON, H.T. Study of bacteriophage types and antibiotic resistance of Staphylococci isolated from dental students and faculty members, $J$. dent. Res., 39:906-11, 1960.

8. MENDONÇA, C.P. Estudos sobre Staphylolococcus aureus (portadores e infecç̄es hospitalares) num hospital geral de Araraquara, SP, 1964-1975. Araraquara, 1976. [Tese de Livre Docência - Fa. culdade de Farmácia e Odontologia de Araraquara]

9. PIOCHI, B.J.A. \& ZELANTE, F. Contribuição para o estudo de Staphylococcus isolados da cavidade bucal. I. Staphylococcus isolados da saliva. Rev. Frac. Odont., S. Paulo, 11:367-78, 1973.
10. PIOCHI, B.J.A. \& ZELANTE, F. Contribuição para o estudo de Staphylococcus isolados da cavidade bucal. III. Staphylococeus isolados da placa dental. Rev. Fac. Odont., S. Paulo, 13:91-8, 1975.

11. SOLE-VERNIN, C. \& UTHIDA-TANAKA, A.M. A prova de Moore conjugada ao antibiograma na identificação das amostras hospitalares e não hospitalares de Staphylococcus aureus. Hospital, Rio de Janeiro, 75:2043-86, 1969.

12. SUBCOMMITTEE ON TAXONOMY OF STAPHYLOCOCCI AND MICROCOCCI. Minutes of First Meeting (5th-6th October, 1964). Int, Bull. bact. Nomecl., $15: 107-8,1965$.

13. WELLER, W.E. Staphylococcal infections. Pediatrics, 23:927-9, 1959.

14. ZELANTE, F.; ASHCAR, H.; PIOCHI, B.J.A. MONSON, C.A. \& CUNHA, P.S. Staphylococcus aureus na boca e no nariz de individuos sãos: verificação de iden. tidade entre as cepas isoladas. Rev. Saude pübl., S. Paulo, 16:92-6, 1982.

Recebido para publicaģão em 28/10/1982 Aprovado para publicacaio em 17/12/1982 